\title{
Correction
}

\section{Correction to: The effect of water content on shear and compressive behavior of polymeric fiber-reinforced clay}

\author{
Mahyar Arabani ${ }^{1} \cdot$ Hamed Haghsheno ${ }^{1}$ (D)
}

Published online: 9 December 2020

(c) Springer Nature Switzerland AG 2020

\section{Correction to: SN Applied Sciences \\ https://doi.org/10.1007/s42452-020-03568-3}

Publisher's Note Springer Nature remains neutral with regard to jurisdictional claims in published maps and institutional affiliations.

The authors' affiliation was incorrect in the initial online publication. The original article has been corrected.

The original article can be found online at https://doi.org/10.1007/s42452-020-03568-3.

Hamed Haghsheno, haghsheno@phd.guilan.ac.ir; Mahyar Arabani, arabani@guilan.ac.ir|'Department of Civil Engineering, University of Guilan, Rasht, Iran. 